This is the final peer-reviewed accepted manuscript of:

Castiglione C, Mazzocchi M. Ten years of five-a-day policy in the UK: Nutritional outcomes and environmental effects. Ecol Econ. 2019;157:185-194. doi:10.1016/j.ecolecon.2018.11.016.

The final published version is available online at:

https://doi.org/10.1016/j.ecolecon.2018.11.016

Rights / License:

The terms and conditions for the reuse of this version of the manuscript are specified in the publishing policy. For all terms of use and more information see the publisher's website.

This item was downloaded from IRIS Università di Bologna (https://cris.unibo.it/)

When citing, please refer to the published version. 


\title{
Ten years of five-a-day policy in the UK: Nutritional outcomes and environmental effects
}

\author{
Concetta Castiglione, Mario Mazzocchi \\ Department of Statistical Sciences, University of Bologna
}

Published on Ecological Economics, 24: 1548-1559 (2015)

DOI: $10.1002 /$ hec.3107

Pre-proof accepted version

\begin{abstract}
This paper estimates the impact of policy measures aimed at increasing fruit and vegetable $(\mathrm{F} \& \mathrm{~V})$ consumption in the UK over more than a decade, evaluating changes in purchased quantities and estimating the corresponding greenhouse gas emissions (GHGEs). We use a counterfactual scenario analysis to isolate the effects of the policy from the influences of evolving prices, incomes and socio-demographic factors. Our estimates suggest that the positive effects of the promotion campaigns on $\mathrm{F} \& \mathrm{~V}$ purchases (about half a portion per adult equivalent per day) still persist 10 years after the start of the policy implementation, and we find no evidence of a wearout effect. We also provide suggestive evidence that the dietary adjustment which accompanies the increase in F\&V intakes translates into a relevant reduction in GHGEs, by an average amount of $3.3 \mathrm{Kg}$. of $\mathrm{CO} 2 \mathrm{e}$ per adult equivalent per month.
\end{abstract}

\section{Acknowledgements}

This research has been carried out within the framework of the SUSDIET Project, which is funded under the ERANET-SUSFOOD Call. The content of this paper reflects only the authors' views and the ERANET-SUSFOOD Consortium is not liable for any use that may be made of the information contained therein. 


\section{Introduction}

Previous research has established that a high consumption of fruit and vegetables has not only a beneficial effect on health, but it also implies lower food-related greenhouse gas emissions (GHGEs) relative to diets heavily based on animal products or cereals (see e.g. Tukker et al. 2011; Milner et al., 2015; Reynolds et al., 2014 and references therein). However, to our knowledge, there is no study explicitly looking at the long-term environmental effects induced by past policies promoting higher fruit and vegetables $(\mathrm{F} \& \mathrm{~V})$ intakes. The ultimate effect of these policies may be different depending on the substitution process, as increased $\mathrm{F} \& \mathrm{~V}$ intake may be associated with higher food consumption (hence higher emissions) or may trigger substitutions from less environmentally-friendly foods (hence lower emissions).

This paper aims to fill this gap in the literature by looking at the effects of more than 10 years of policy measures aimed at increasing F\&V consumption in the UK. We use a counterfactual scenario analysis to separate the policy effects from the influences of evolving prices, incomes and socio-demographic factors, and consider substitutions between food groups in the evaluation of the ultimate GHGE outcome.

A better understanding of the connection between diets, health and sustainability is central to guide the governance of food systems. In that respect, the UK provides an ideal research setting, with an established nutrition policy mix (Jebb et al., 2013) ${ }^{1}$, relatively detailed information on food consumption, and local estimates of the GHGEs associated with food production.

Several studies have investigated the potential effect on emissions of adjusting diets to meet the nutritional guidelines. A simulation by Irz et al. (2016) predicts that a $5 \%$ increase of $\mathrm{F} \& \mathrm{~V}$ intakes in France could result in a reduction of $2.8 \%$ in $\mathrm{CO} 2$ emissions. For the UK, Green et al. (2015) estimate that meeting the WHO guidelines for better nutrition could generate a 17\% reduction in GHGEs. Similar conclusions on the sustainability of diets that are optimal from a nutrition perspective were reached in simulations for other countries (van Dooren et al., 2014; Wilson et al, 2013; Hallström et al., 2014). However, these projections assume substitution processes that are not

\footnotetext{
${ }^{1}$ See also UK Cabinet Office 2008 report "Food Matters: Towards a Strategy for the $21^{\text {st }}$ Century", pages 41-44, webarchive.nationalarchives.gov.uk
} 
straightforward and may be even unrealistic given habits, prices and budget constraints (Masset et al., 2014; Green et al., 2015). Our analysis aims to contribute to this debate by looking at the actual substitutions and food basket modifications that have occurred during the implementation of the UK 5-a-day policy.

Dietary changes are usually small in the short term, and habits and prices are more influential forces than policy actions. A 2010 survey has shown that European countries have implemented more than 100 national-level interventions to encourage the consumption of healthy foods (Capacci et al., 2012). According to the Nourishing Framework database ${ }^{2}$, the UK has adopted at least 15 national-level policy actions to improve diet quality over the last 20 years, including a salt reduction social marketing campaign from 2004 (Shankar et al., 2013), Healthy Start vouchers to support pregnant women and families with young children from 2006 (Lucas et al., 2015), and restrictions on food advertising to children implemented since 2007 (Silva et al., 2015). Furthermore, the UK government was one of the first EU members to launch a sustainable development strategy in 1994 (Russel, 2007).

However, if one compares official consumption statistics from the Department for the Environment, Food and Rural Affairs (DEFRA) ${ }^{4}$, changes have been small. For example, in 1995 the average UK consumption of meat, fish and fruit was 986, 147 and 1068 grams per person per week, respectively. In 2015, the respective values were 929 , 146 and 1093. Over 20 years, fruit consumption went up by less than 4 grams per person per day, fish consumption was stable and meat consumption went down by a little more than 8 grams per person per day. There are some relevant dynamics behind these trends. Empirical evidence shows that UK policies aimed at promoting F\&V intakes have been effective, at least in the short-term, but their positive impact has been mitigated by market forces, income dynamics and rising prices (Capacci and Mazzocchi, 2011; Bremner et al., 2006; Jones et al., 2014).

Reductions in food-related GHGEs necessarily require a lower consumption of animal products, and these patterns are also influenced by social and economic drivers. Several key trends were identified in the review by Hoolohan et al. (2016). For example,

\footnotetext{
${ }^{2}$ http://www.wcrf.org/int/policy/nourishing-framework

3 The UK was preceded by the Netherlands with the 1989 National Environmental Plan (National Milieubeleids Plan, see Bennett, 2010)

${ }^{4}$ https://www.gov.uk/government/collections/family-food-statistics
} 
consumption of ready meals and convenience foods has been constantly increasing in the UK, and the share of animal product-based ingredients in these product plays an important role in this. Other consumption behaviours with an impact on emissions are related to the globalization of food trade and longer geographical distances between producers and consumers, and - not independently from this pattern - changes in the seasonal consumption patterns.

The assumption in most studies is that higher intakes of $\mathrm{F} \& \mathrm{~V}$ lead to lower emissions because of lower consumption of animal products. However, there is research suggesting that the environmental benefits might be offset if this additional consumption is covered by imported $\mathrm{F} \& \mathrm{~V}$ and off-season production. The latest consolidated statistics $^{5}$ show that the UK imports about $85 \%$ and $54 \%$ of the domestic demand for fruit and vegetables, respectively. According to Garnett (2006), consumption of F\&V accounts for about $2.5 \%$ of UK total GHGEs, especially due to transport emissions. Global trading has increased the weight of these emissions, as food and especially F\&V are transported over much longer distances than in the past (Michalsky and Hooda, 2015; Sim et al., 2007; Cowell and Parkinson, 2003). The environmental impact of increased imports and off-season consumption has been the target of various studies (see e.g. Milà i Canal et al., 2007) despite the difficulty of accessing adequate data on transport and energy use at the different stages of the supply chain and consider trade-offs between emissions from potentially less intensive production systems in the country of origin and those associated with long-distance (especially air freight) transport (Avetisyan et al., 2014; Milà i Canal et al., 2008). The rationale behind this study is that social norms, attitudes and values may act on consumer choices as strongly as prices and incomes (Vermeir and Verbeke, 2006) and social marketing actions are major instruments used to achieve positive changes. As the promotion of $\mathrm{F} \& \mathrm{~V}$ intakes is a key element of policies targeting diets and nutrition-related diseases, this study aims at: (a) estimating the extent of the dietary changes induced by the $\mathrm{UK} F \& \mathrm{~V}$ promotion policies in the longer term (2003-2014) relative to previous evaluations, and net of the food price effects and income dynamics observed during this period; (b) translate these changes into GHGE estimates. Our study exploits information from the UK household budget surveys. Although the

\footnotetext{
${ }^{5}$ Our processing on data from DEFRA (Horticulture Statistics, https://www.gov.uk/government/collections/horticultural-statistics)
} 
nature of our data does not allow for a precise quantification of the marginal contribution to GHGEs from additional F\&V imports and off-season consumption, we provide descriptive evidence on these trends to check for the robustness of our findings.

\section{The UK 5-a-day policy and fruit and vegetable consumption trends}

The "5-a-day" programme, first launched in the US in 1991 and subsequently embraced by several other countries (Stables et al., 2002), aims at increasing fruit and vegetable intakes towards the World Health Organization (WHO) recommendation of 5 portions (or 400 g) per day (WHO, 2003). These campaigns have proved to be moderately effective and highly cost-effective, not only by enhancing consumer awareness, but also in terms of increased $\mathrm{F} \& \mathrm{~V}$ intakes, estimated at around 0.6 servings (48 grams) per person per day (Ammerman et al., 2002). For example, the Western Australian "Go for $2 \& 5$ " campaign, started in 2002, was based on a multi-strategy social marketing approach quite similar to the one adopted by the UK. Over the first three years of implementation, the Australian campaign resulted in an average increase in F\&V intakes of 0.8 servings (64 grams) per person per day (Pollard, et al., 2011).

In the UK, a 5-a-day campaign was launched at a national level on $25 \mathrm{March} 2003$. This policy targets the population at large, although the programme had specific initiatives for children and elderly people. Capacci and Mazzocchi (2011) estimated that after three years the campaign had generated 0.3 extra portions of fruit and vegetables on average, and evaluations in other countries report similar effect sizes. This estimate reflects the additional consumption generated by the campaign after controlling for changes in prices and incomes.

When one looks at the actual consumption levels, the data show that $F \& V$ purchases went up from 4.05 portions per person per day in 2003 to 4.38 in $2006^{6}$, then they started to decline, and the latest figure of 3.92 in 2015 is lower than the precampaign level. Purchases are gross of food waste, and figures from the National Diet and Nutrition Survey (NDNS, NatCen, 2018) suggest lower intakes, but they confirm that any increase in $F \& V$ intake is limited to the initial five years after the launch of the

6 Estimates based on food purchase data from the Family Food Survey (https://www.gov.uk/government/uploads/system/uploads/attachment_data/file/597712/familyfood2015-webtables-09mar17.ods), according to the definition 1 portion $=80$ grams. 
campaign. The 2002 NDNS data report that the median intake for adults in the 19-64 age range was 2.3 portions when including fruit and vegetables from composite dishes, and only $14 \%$ of individuals met the 5 -a-day guideline. The $2008-10$ figure $^{7}$ is much higher for the same group, with a median intake of 3.7 portions and $29 \%$ meeting the target (Office for National Statistics, 2002). The latest data (from the 2012-14 wave of the NDNS) indicate the same median consumption, and a reduction to $27 \%$ in the proportion of individuals meeting the 5-a-day target (Office for National Statistics, 2014).

\section{[Figure 1 about here]}

Figure 1 shows consumption of six foods (fruit, vegetables, beef and lamb, chicken, composite dishes and non-alcoholic drinks) over the period 2001-2014 in the UK, based on average purchased quantities as measured by the UK household budget surveys (Office for National Statistics, 2017), using 2002 as the base year. These data indicate that consumption of fruit and vegetables reached a peak in 2005 and 2006, and declined afterwards. During the same period, purchases of beef and lamb also exhibit a turning point and a reversal in their trend, as they decline sharply from 2006 onwards. These patterns are a combination of a variety of trends impacting consumer choice (see e.g. Hoolohan et al., 2016), and the influence of the economic recession, as income shocks have shifted diets towards cheaper calories and a reduction in fruit and vegetable intakes (Griffith et al., 2013 and 2016).

Whether the continuing 5-a-day program may have mitigated the negative effects of economic recession on $\mathrm{F} \& \mathrm{~V}$ intakes, and the extent of the influence of the crisis affecting meat consumption relative to other factors are open questions. Our counterfactual approach aims at eliciting the effects of the policy, net of any price and income dynamics that may have been driven by the crisis.

Over the first three years of the UK 5-a-day campaign, the government spent about $£ 3.3$ million for a set of promotional activities. The programme has continued, but it has evolved since its introduction. Since 2008, the 5-a-day campaign has been maintained as a local promotion intervention, and its initiatives merged into broader

\footnotetext{
${ }^{7}$ From the 2008-9 edition, the NDNS has been revised, the main change being the transition from a periodic survey to a yearly (rolling) survey.
} 
lifestyle programmes such as Change4Life (Manning, 2016). During the same time span, other initiatives have targeted consumer attitudes and preferences for fruit and vegetable consumption, including the UK school fruit scheme, a major action funded with about $£ 40$ million per year through the National Lottery (Jebb et al., 2013).

\section{Materials \& Methods}

\subsection{Data}

The data used in this analysis are taken from the Expenditure and Food Survey (EFS) and the Living Cost Survey (LCS) conducted by the Office for National Statistics (ONS) and DEFRA in the UK, over the period 2001-2014 (Office for National StatisticsDEFRA, 2017). ${ }^{8}$ In relation to the objectives of our study, data from household surveys are preferred to alternative sources of information on diets (e.g. the Diet \& Nutrition Survey, NDNS) for several reasons: (a) they refer to purchases, hence they include household-level waste that may be important for fresh foods and is relevant to the estimation of GHGEs; (b) they are conducted on a regular yearly basis, whereas the UK NDNS has been running on a yearly basis only from 2008; (c) information on prices, incomes and food expenditure are key to our modelling approach and they are only available from household budget data.

The EFS changed from a financial to a calendar year based system in 2006. Our analysis is based on the micro-level (household-level) data, and after combining the 13 surveys into a single data-set, we refer to the calendar years. The resulting sample size by year and quarter is displayed in Table A1 in the Appendix.

EFS and LCS purchase data are collected from a sample of households using diaries of food purchases over a 2-week period (Burgon, 2007). Every year between 5,000 and 6,000 households interviewed from the UK population, and the multi-stage stratified random sampling strategy is designed to guarantee that the sample is representative of all UK households in each quarter of the year (Office for National Statistics, 2012).

\footnotetext{
${ }^{8}$ From January 2008, the EFS became known as the Living Costs and Food (LCF) module of the Integrated Household Survey (IHS).
} 
Data are available at the household level and include expenditure values and purchased quantities in grams. Food products are classified according to the five-level EUROSTAT Classification of Individual Consumption by Purpose (ECOICOP). The EFS and LCS samples are nationally representative and sampling weights are provided for each household in the data-set.

For the purpose of this analysis we consider eighteen food aggregates ${ }^{9}$, a residual category (miscellaneous food $)^{10}$, and a further disaggregation level (ECOICOP-5 digits) for the fruit and vegetables categories ${ }^{11}$. Unit values for each household and food are computed as the ratio between expenditure and purchased quantities. By their nature, unit values reflect both the price dimension and a quality choice component, and the latter is especially relevant when composite food groups are considered. As households make different quality choices, and they choose different product mixes within the same food aggregate, unit values need to be cleaned from this additional noise when the objective is to measure market prices. This issue is commonly addressed by assuming that households living in the same place and time period face the same prices. Thus, a quality-adjusted estimate of prices is obtained by averaging the unit values by month and geographical area (13 UK government office regions). Finally, expenditures and incomes are normalized by the adult-equivalent OECD coefficients (OECD, 2009), to account for economies of scale in household consumption ${ }^{12}$.

\footnotetext{
91 - Fruit; 2 - Vegetables; 3 - Potatoes; 4 - Cereals; 5 - Beef and lamb; 6 - Chicken; 7 - Pork; 8 - Other meats; 9 - Fish; 10 - Milk and yoghurt; 11 - Butter, cheese \& other dairy; 12 - Eggs; 13 - Oils and fats; 14 - Composite dishes; 15 - Alcoholic drinks; 15 - Alcoholic drinks; 16 - Non-alcoholic drinks; 17 Confectionery; 18 - Crisps and snacks.

${ }^{10}$ Miscellaneous foods include: Tea; Coffee beans and ground coffee; Instant coffee; Coffee essences; Cocoa and chocolate drinks; Malt drinks \& chocolate versions of malted drinks; Fruit teas, instant tea, herbal tea, rosehip tea; Invalid foods, slimming foods and sports foods; Sauces; Takeaway sauces and mayonnaise; Stock cubes and meat \& yeast extracts; Salt; Spices and dried herbs; Bisto, gravy granules, stuffing mix, baking powder, yeast.

${ }^{11}$ Fruit: 1 - Fresh citrus fruits; 2 - Apples and pears; 3 - Stone fruits \& grapes; 4 - Berries; 5 - Bananas; 6 -Melons; 7 - Tinned fruit; 8 - Dried fruit; 9 - Frozen fruit. Vegetables: 1 - Salad; 2 - Prepared vegetables; 3 - Tomatoes; 4 - Other vegetables; 5 - Mushrooms; 6 - Tinned vegetables; 7 - Frozen vegetables; 8 Dried vegetables; 9 - Other roots

12 The OECD equivalence scale assigns a weight equal to 1 to the first household member, and 0.7 to each additional adult, whereas every child has a weight of 0.5 . Results without the application of the equivalence scale are available in the on-line Appendix, see Tables C and D.
} 


\subsection{Evaluation strategy}

Our evaluation of the effects of the 5-a-day programme rests on the estimation of a counterfactual scenario (Heckman, 2008). In other words, we simulate what would have happened to $\mathrm{F} \& \mathrm{~V}$ (and other food) purchases without the 5-a-day policy.

To this purpose, we: (a) define baseline consumption and its relation with varying socio-economic variables (prices, incomes, household characteristics) according to a theory-consistent utility maximization demand model that allows us to explore substitutions in response to changes in these variables; (b) estimate the model on data prior to the introduction of the 5-a-day programme to capture the structure of preferences in absence of the policy; (c) estimate the model on data after the introduction of the policy; (d) estimate the policy effects in each time period as the difference between the predictions from the model in step (c) and the model in step (b) using price, income and household characteristics data from the same time period. By conditioning on the socioeconomic variables, this difference only reflects the change in consumer preferences induced by the policy, i.e. it represents the shift in consumption that can be ascribed to the policy when prices, incomes and household characteristics are held constant.

As in Capacci and Mazzocchi (2011), the counterfactual (baseline) model is the following Almost Ideal Demand System (AIDS, Deaton and Muellbauer, 1980):

$$
w_{i h t}=\alpha_{i}+\boldsymbol{\tau}_{i} \mathbf{z}_{h}+\sum_{j=1}^{n} \gamma_{i j} \ln p_{j h t}+\beta_{i} \ln \left(\frac{x_{h t}}{P_{h t}}\right)+\varepsilon_{i t}
$$

Where:

$w_{i h t}$ is the share of total food expenditure paid by household $h$ to purchase food $i$ at time $t$.

$\mathbf{z}_{\boldsymbol{h}}$ is a vector of household characteristics to capture the variation in expenditure shares across households which can be explained by heterogeneity in the household sociodemographic characteristics and changes in the sample composition over time;

$p_{j h t}$ is the price for the $j$-th food faced by household $h$ at time $t$;

$x_{h t}$ is the total food budget spent by household $h$ at time $t$;

$P_{h t}$ is the AIDS non-linear price index for household $h$ at time $t$. 
The model coefficients $\left(\alpha_{i}, \tau_{i}, \gamma_{i j}, \beta_{i}\right)$ reflect the structure of preferences for a utilitymaximizing consumer and are empirically estimated via maximum-likelihood on the data, and $\varepsilon i t$ is a random error term.

The set of household characteristics in $\mathbf{z}_{\boldsymbol{h}}$ include age in years, age at which education was completed, marital status and job status (working, retired, unemployed) of the household reference person, and a binary variable indicating the presence of children aged less than 18 in the household. To address the endogeneity of the total food budget $x_{h t}$, we exploit per-capita household income as an instrument.

As discussed, our estimate of the 5-a-day effect is the difference in the post-policy predictions obtained using the post-policy model parameters relative to the predictions from the pre-policy model parameters.

More specifically, the AIDS model is estimated on the sample of observations not exposed to the policy (BEFORE model - 2001 to March 2003) and after the policy (AFTER model - April 2003-December 2014). Two sets of consumption predictions are then obtained over the post-policy period (again, April 2003 to December 2014) based on the parameters from the BEFORE and AFTER models, respectively. The computation of predicted quantities $\hat{q}_{i h t}$ from predicted expenditure shares $\widehat{w}_{i h t}$ is based on the current prices and total expenditure, $\hat{q}_{i h t}=\widehat{w}_{i h t} \cdot x_{h t} / p_{i t}$.

The difference between the predictions from the two models is the estimated policy impact:

$\hat{\delta}_{i h t}=\hat{q}_{i h t}^{A F T E R}-\hat{q}_{i h t}^{B E F O R E}$

Since the 5-a-day campaign may not only have impacted on aggregate purchases of fruit and vegetables, but it might also have altered the composition of the fruit and vegetable basket, we extend the evaluation approach to include a second stage aimed at eliciting the effects of the policy on the expenditure shares of disaggregated types of fruit and vegetables. The procedure is the same as for the first step, but the AIDS model in (1) is conditional on fruit and vegetable expenditure, i.e. $x_{h t}$ now represents the total expenditure in fruit and vegetables by household $h$ at time $t$. As in the previous step we obtain the prediction of F\&V expenditure shares $\left(\widehat{w}_{i h t}^{B E F O R E}\right.$ and $\left.\widehat{w}_{i h t}^{A F T E R}\right)$ based on the parameters from the BEFORE and AFTER models, respectively. Using these shares, it 
is straightforward to estimate the change in the purchased quantities for each specific type of fruit and vegetables.

\subsection{Effects on greenhouse gas emissions}

The final step of our analysis is to convert the estimated quantities into greenhouse gas emissions (GHGEs) measured in terms of carbon dioxide equivalent $(\mathrm{CO} 2 \mathrm{e})$. To this purpose we apply emission factors obtained from Hoolohan et al. (2013). These emission factors are based on estimates of the emissions associated to the various stages of the supply chain from production to the retailer shelf. Thus, for each food category, the emission factor is the sum of different Life Cycle Assessment stages (farming and processing, transit packaging, consumer packaging, transport, warehouse and distribution, refrigeration, overheads). Hoolohan et al. (2013) provide estimates for 66 food categories, based on the evaluation of a mid-sized UK supermarket's product supply chains. Transport emissions take into account the origin of the representative products and the transport means, hence they are higher for imported foods.

Since these emission factors are sometimes provided at a more disaggregated level than our food groups, aggregate GHGE factors were computed by weighting the original emission factor by the purchased quantity of each specific food as obtained from our data, according to the following equation:

$G H G E_{i}=\sum_{j=1}^{n} G H G E_{H j} \cdot \frac{q_{j}}{\sum_{k=1}^{n}\left(G H G E_{H k} \cdot q_{k}\right)}$

where $G H G E_{i}$ is the aggregate emission factor, $G H G E_{H j}$ is the emission factor for the specific food $j$ (with $j: 1, \ldots, n$ ) as reported in Hoolohan et al. (2013), and $q_{j}$ is the average quantity of the $j$-th food purchased in the UK in 2014.

For example, the GHGE factor for cereals is the weighted average of the GHGE factors across several cereal products (e.g. bread, rice, pasta, other cereals, etc.). The emission factors for each composite food group are reported in Table 1, together with those for the fruit and vegetable products that were maintained at the highest disaggregation level. Animal products have the highest GHGE impact (especially meats and dairy product), whereas potatoes, crisps $\&$ snacks and non-alcoholic drink have the 
lowest emission factors. Finally, the estimated impact of the policy in terms of GHGEs can be simply obtained as:

$\eta_{i h t}=\hat{\delta}_{i h t} \cdot G H G E_{i}$

[Table 1 about here]

\section{Results and discussion}

Descriptive statistics for our data are shown in Table 2 and include information on purchased quantities, estimated prices, and the conversion of quantities into GHGEs using the emission factors described in Section 3.3. The available sample contains 84,356 households. Table 3 reports the sample sizes and average household characteristics considered in our estimation for the full sample, pre-policy period and post-policy period, respectively. The estimation period prior to the introduction of the 5-a-day policy includes observations for the two-year period between April 2001 and March 2003. Although this is a short period relative to the post-policy time windows, it includes information on the purchases and characteristics of 14,381 households. In relation to the observed characteristics, Table 3 shows that they are quite stable between the pre-policy and the post-policy period, and once inflation is controlled for, even income and food expenditure do not exhibit substantial changes between the two sub-periods.

[Table 2 about here]

[Table 3 about here]

\subsection{Impact on purchases}

We estimate the impact of the 5-a-day policy in terms of purchased quantities for each food group, and the resulting GHGE effects over three different prediction samples: the full post-policy sample (years 2003-2014) and two sub-samples (2003 to 2008 and 2009 to 2014), in order to check for the declining effects of the campaign over time. 
[Table 4 about here]

Table 4 shows the average quantity effect associated with the 5-a-day policy over the three sub-samples. Our estimates show that the evolution of preferences during this period has had a significant impact on the allocation of the food basket across the food groups. The values refer to 'adult-equivalent' consumption ${ }^{13}$, and show that on-average the changes in preferences during the 5-a-day campaign accounted for an increase in F\&V purchases of about $1.17 \mathrm{Kg}$ per adult per month, which corresponds to 38.5 grams per day, about half a portion. This estimate is slightly higher than the one obtained by Capacci and Mazzocchi (2011) for the period 2004-2006 (0.3 portions), and in line with estimates of the effect of $F \& V$ promotion campaigns in other countries (see e.g. the review in Ammerman et al., 2002 and Pomerlau et al., 2005). When the sample is broken down into two sub-periods, there is no compelling evidence of a decline in impact, and actually our model estimates a larger effect on the 2009-2014 period (1.07 Kg per month or 35 grams per day) than in the $2003-2008$ period ( $0.87 \mathrm{Kg}$. per month or 29 grams per day). Thus, comparing these estimates to the actual consumption levels, it would seem that the positive effect of the campaign is structural and stable, but the negative effect of recession on incomes and/or price changes have prevented $\mathrm{F} \& \mathrm{~V}$ consumption from remaining at the pre-crisis levels.

[Table 5 about here]

Table 5 reports the impact of the policy on disaggregated fruit and vegetable products for the full post-policy sample ${ }^{14}$. The estimated effect is positive for all fruit types except tinned fruit, which remained stable, and a larger response (above 100 grams per person per week) is observed for citrus fruits, apples and pears, berries, stone fruits and bananas. Within the vegetables group, we found the largest increase for tinned

\footnotetext{
${ }^{13}$ Adult-equivalent values are obtained through the OECD scale described in footnote 8 , which implicitly assumes that purchases for child consumption are half of those of the first adult in the household. Household-level impact estimates without the application of equivalence scales are provided in the on-line Appendix, see Tables C and D.

${ }^{14}$ Detailed results on the two post-policy sub-samples are available as supplemental on-line material, see Tables A and B in the on-line Appendix.
} 
vegetables (e.g. canned tomatoes) and for the miscellaneous vegetables (beans, peas, cucumbers, courgettes, cauliflower, etc.) and roots (carrots and other roots) categories, whereas the change in other categories was negligible and even slightly negative for some products such as tomatoes (a reduction of 74 grams per person per month), frozen vegetables (-32 grams per month) and salads (-15 grams per month).

\subsection{Consumer substitutions in relation to imports and seasonality}

UK consumption of fruit and vegetables heavily depends on imports. Considering imports in relation to domestic consumption (Table 6), $86.2 \%$ of the fruit and more than half of the vegetables consumed or processed in the UK were imported over the period 2009-2014.

[Table 6 about here]

This dimension must be accounted for when considering the GHGEs associated with the substitution process described in Section 4.1. The emission factors provided in Hoolohan et al. (2013) incorporate the higher transport emissions for imported foods, based on the origin for a range of products sold in a mid-size UK supermarket within each relevant food category, as evaluated at the time of the study ${ }^{15}$. As the incidence of imports for a given food category may change over time, especially in response to demand shifts, the transport emission factor may also be affected. Considering the trends shown in the last three columns of Table 6 , it seems unlikely that the evolution of imports may have altered emission factors in a relevant way, since the relative weight of imported fruit and vegetables appears to be quite stable, with few exceptions.

The larger demand for apples and pears over the time window 2009-2014 was only partially covered by imports, so that the proportion of imports fell from $76.2 \%$ of the 2003-2008 period to $61.8 \%$. Even considering the overall fruit demand, the dependence on imports decreased from $92 \%$ in $2001-2002$ to $86.2 \%$ in $2009-2014$. Considering other fruits that have seen an increase in demand following the 5-a-day

\footnotetext{
15 Transport emissions were estimated through some necessary simplification, as the 2004 average emission for UK transport means were considered, regardless of the country of origin of the foods.
} 
campaign, their dependence of imports was either already above $100 \%$ before the policy implementation (citrus fruit, stone fruits and bananas) or their trend has been stable (berries), which confirms that Hoolohan's emission factors should remain valid. Among vegetables, there is evidence of rising incidence of imports for the aggregate category "other vegetables", with an increase from $47.5 \%$ in $2001-2002$ to $55.7 \%$ in $2009-2014$. Considering roots, the other category for which we estimated a major increase in demand, we observe a decrease in the incidence of imports. On balance, given the structural dependence of UK on imports, any increase in demand for fruit and vegetables is indeed associated with an increase in transport emissions, but the emission factors per unit that we adopt in our estimates are inclusive of the import dimension.

Similarly, higher demand for fruit and vegetables and substitution patterns across the individual $\mathrm{F} \& \mathrm{~V}$ categories may be accompanied by a change in the seasonal consumption patterns, which in turn would have implications for the estimation of GHGEs. More specifically, off-season consumption is likely to be associated with production in heated greenhouses, long-distance transport or cold storage (see e.g. Macdiarmid, 2014; Röös, E., \& Karlsson, H., 2013). Thus, we explore the evolution of seasonal patterns in consumption by regressing purchased quantities for individual $\mathrm{F} \& \mathrm{~V}$ categories on quarterly binary variables and fixed year effects over different subsamples ${ }^{16}$. This basic analysis allows to identify clear seasonal patterns for most fruit and vegetables categories. Consumption of berries, melons, prepared vegetables and tinned vegetables is higher during the warmer months of the year, whereas citrus fruits, roots and other vegetables are more popular in winter. Our estimates highlight a major increase in off-season consumption for berries, and - over the more recent years - for roots. Purchases of berries were 10 times higher in spring and summer relative to the rest of the year in 2001-2002, by 2009-2014 the ratio has reduced to 2.3. Similarly, purchases of roots used to be $43 \%$ higher in autumn and winter in 2001-2002, but the distance has shortened to $18 \%$ over the last period of our analysis. Interestingly, consumption in both of these groups mostly relies on home production (see Table 6) which reduces the risk of higher emission because of long-distance transports, although other factors (e.g. greenhouse heating) may still be relevant. There is a scarcity of comprehensive LCA

\footnotetext{
${ }^{16}$ Estimates for the pre-policy period and the two post-policy sub-samples are available as supplemental on-line material, see Table $\mathrm{E}$ in the on-line Appendix.
} 
studies on the effects of off-season consumption of F\&V in terms of GHGEs, but some case studies such as Foster et al. (2014) on UK-produced raspberries are relevant to our analysis. Foster et al. find that the increase in emissions is small (less than $4 \%$ ), but their study does not contemplate the possibility of heated greenhouses for off-season production. The evidence on the additional GHGEs linked to off-season greenhouse production is incomplete, but according to figures reported in a recent review by Parajuli et al. (2019), the gap in farming emissions between greenhouse-produced vegetables (reported examples refer to beans, lettuce and tomatoes) and those reported in Hoolohan et al. (2013) are not large, since the latter already embody estimates for production in heated greenhouses, based on the seasonal consumption patterns at the time of their study. Still, we consider the major change in seasonality for berries and roots when evaluating the impact of increased demand on emissions.

\subsection{Impact on GHGES}

In order to translate the effects of the preference changes observed during the 5-a-day campaign into GHGEs, we consider substitutions within the F\&V group and across the aggregate food groups that have occurred over the same period. We do not claim that changes in purchases of other foods than F\&V should be ascribed to the policy, but our model provides information on the substitutions that have occurred over the considered decade, relative to the pre-campaign preferences, and controlling for price and income changes. Over the whole period of analysis, as one would expect, many groups do not emerge as responsive to the $\mathrm{F} \& \mathrm{~V}$ promotion campaign (i.e. we estimate a change lower than 100 grams per capita per month), and total food purchases are stable. Exceptions are potatoes (a decrease by 335 grams per month per adult equivalent), confectionery (428 grams), cereals (-213 grams), pork (-128 grams), and the only relevant increase is registered for alcoholic drinks (+372 grams). Overall, we estimate a significant decrease in purchases for 15 out of 17 groups, and the net outcome is a reduction of GHGEs estimated at $-3.66 \mathrm{Kg} \mathrm{CO} 2 \mathrm{e}$ per adult per month, as shown in Table 7. Even considering the higher imports of vegetables, and the relevant changes in seasonality for berries and roots, the net reduction of emissions would remain important. Under a very conservative assumption that GHGEs double up for these three groups, one would still observe a net outcome of $-2.96 \mathrm{Kg} \mathrm{CO} 2 \mathrm{e}$ per adult per month. 
[Table 7 about here]

When the two sub-samples are considered, there are some conspicuous differences. Over the first sub-sample (2003-2008), the negative impact on potatoes and cereals is stronger, and the model also estimates a major reduction of milk and yogurt ($1.04 \mathrm{Kg} \mathrm{CO} 2 \mathrm{e}$ per month per adult equivalent). These changes translate into a reduction in GHGEs by $4.27 \mathrm{Kg}$. CO2e per adult equivalent per month. Over the period 2009-2014, hence during the economic recession, it appears that estimates for potatoes and cereals switch to a positive and significant effect (136 grams and 291 grams per month, respectively). Considering that these food groups are staples, it is likely that our counterfactual model cannot fully capture the changes in preferences generated by the financial crisis. Nevertheless, the overall effect on GHGEs is still positive from an environmental perspective, with a reduction of $3.23 \mathrm{Kg}$. CO2e per adult equivalent per month. The food groups that consistently bring the largest contribution to the reduction in GHGEs through a decrease in purchased quantities are confectionery and pork. Among other animal products, beef and lamb show a major decline over the 2009-2014 period relative to a negligible consumption change over the 2003-2008 period. On the contrary, dairy products switch from major decreases in the years following the introduction of the 5-a-day policy to an increase in purchases and GHGEs through the second sample.

\section{Conclusion}

In this work we evaluate the 5-a-day campaign over a longer period (2003-2014) relative to previous evaluations, and translate its outcomes in terms of purchased quantities into environmental impacts as measured by GHGEs, based on emission factors provided in the literature and allowing for substitutions across food groups.

Our evaluation rests on model-based counterfactual estimates. The advantage of this approach is that it controls for changes in the main drivers of food consumption, prices, incomes and other socio-demographic characteristics that have evolved over this long timespan. This is particularly relevant for our analysis, as various data sources point out an initial positive impact of the UK 5-a-day campaign in terms of F\&V intakes that 
wears out over a longer horizon, to the point that nutrition surveys and household budget surveys suggest that consumption levels have been stationary - if not decreasing - over the period 2008-2014. Since this time window is one of recession, a counterfactual analysis is more informative about the persisting or declining effect of the promotion campaign.

Our evidence suggests that the positive impact of the 5-a-day campaign on F\&V purchases remains significant over the years of the economic recession after one controls for income and price changes, and that the average effect is an increase in consumption estimated at around half a portion per day per adult equivalent, higher than previous short-term estimates and in line with international studies on similar promotion campaigns.

The estimated GHGEs effects necessarily rest on the assumption that our counterfactual model is able to isolate the impact of the 5-a-day campaign from other confounding factors and trends than those that enter the model. While we are able to account for changes in prices, incomes and other relevant economic variables (e.g. unemployment), it is obvious that consumers have been exposed to a great amount of information over the same period, e.g. about the negative effects of salt, fat, and sugar intakes. However, there is little evidence of major changes in UK dietary patterns over the decade we consider in our sample. Whitton et al. (2011) exploit data from the UK Diet \& Nutrition Surveys to compare dietary intakes between 2008 and 2001, and do not find any significant change in intakes of adults at the food group level, and relatively small changes for children, which makes our assumption credible, at least for the years between 2003 and 2008. Over the subsequent years, UK diets have been affected by the economic recession (Griffith et al., 2013), and our evaluation approach is designed to control for changes in food purchases induced by income and price shocks. Nevertheless, we acknowledge that it would be pretentious to assume that the observed substitutions, especially the reduction in meat and confectionery purchases, are exclusively induced by a campaign targeting $\mathrm{F} \& \mathrm{~V}$ intakes ${ }^{17}$. A further assumption behind our estimates is that GHGEs of food products are constant over time, as we apply a single set of emission

\footnotetext{
${ }^{17}$ Increasing trends in the rate of vegetarian and vegan households as captured by our data do not seem sharp enough to generate concerns. Households not purchasing meat were $7.2 \%$ in $2001,7.6 \%$ in 2008 and $7.7 \%$ in 2014 , while households not purchasing meat, fish, dairy and eggs were $0.8 \%$ in $2001,0.9 \%$ in 2008 and $0.8 \%$ in 2014 .
} 
factors for the whole period. While this is a necessary assumption as detailed information on trends is missing, the emission factors from Hoolohan et al. (2013) are derived from studies published between 2003 and 2010 and they should represent a reasonable approximation for the average emissions during the time window of our analysis. Furthermore, we explore the potential effect of higher demand for F\&V in terms of dependence on imports and increases of off-season consumption, as both trends would translate into higher GHGEs. We provide descriptive evidence that imports of vegetables and off-season consumption of berries and roots have increased relative to the pre-policy period, and we show that allowing for higher GHGEs for these groups has a limited impact on our total estimates. Still, our evaluations are constrained by the lack of information on the origin of products in household budget surveys, quantification of specific F\&V emission factors depending on farming methods and country of origin is still incomplete, and we acknowledge this limitation.

Hence, our estimates reflect the potential contribution to the reduction of GHGEs due to changes in consumer preferences, but further reductions may be achieved by acting on pre-purchase emission-reduction actions acting for example on food chain waste, production and processing technologies and logistics (Garnett, 2011). Furthermore, promoting F\&V with a focus on local and seasonal consumption is likely to generate even larger benefits. Still, our evaluation captures the combined effects of preference changes after controlling for economic drivers, and provides suggestive evidence that increases in $\mathrm{F} \& \mathrm{~V}$ intakes are accompanied by an overall reduction in GHGE emissions. The uncertainty in the size of these effects derives from limitations on information from product origins and the level of aggregation in consumption data, but the growing availability of highly detailed commercial data like those supplied within home scan surveys might open the way to more accurate evaluations.

Our results have two immediate policy implications: first, we show that a prolonged effort in promoting $\mathrm{F} \& \mathrm{~V}$ intakes continues to be effective over time; second, based on the UK evidence, we confirm previous findings that policies aimed at promoting F\&V consumption are beneficial from both the health and environmental perspectives, especially when the focus of promotion is on seasonal and local consumption. 


\section{References}

Ammerman, A.S., Lindquist, C.H., Lohr, K.N., Hersey, J., 2002. The Efficacy of Behavioral Interventions to Modify Dietary Fat and Fruit and Vegetable Intake: A Review of the Evidence, Preventive Medicine, 35, 25-41, DOI:10.1006/pmed.2002.1028.

Avetisyan, M., Hertel, T., Sampson, G., 2014. Is Local Food More Environmentally Friendly? The GHG Emissions Impacts of Consuming Imported versus Domestically Produced Food. Environmental Resource Economics, 58: 415-462. DOI:10.1007/s10640-013-9706-3

Bennett, G., 2010. The History of the Dutch National Environmental Policy Plan, Environment: Science and Policy for Sustainable Development, 33(7): 6-33. DOI: 10.1080/00139157.1991.9929979.

Blundell, R., Costa Dias, M., 2009. Alternative Approaches to Evaluation in Empirical Microeconomics. International Journal of Human Resources 44(3): 565-640. DOI: 10.1353/jhr.2009.0009.

Boffetta P., Couto, E., Wichmann, J. et al., 2010. Fruit and vegetable intake and overall cancer risk in the European Prospective Investigation into Cancer and Nutrition (EPIC). Journal of National Cancer Institute 102(8): 529-537. DOI: 10.1093/jnci/djq072.

Bremner, P., Dalziel, D., Evans, L., 2006. Evaluation of the 5-a-day programme. Final Report. In: Evaluation and Research Team. Big Lottery Fund, London.

Burgon, C., 2007. Introduction to the expenditure and food survey. Nutrition Bulletin 32(3): $283-$ 286. DOI: $10.1111 / \mathrm{j} .1467-3010.2007 .00647 . x$.

Capacci, S., Mazzocchi, M., Shankar, B., Brambila Macias, J., Verbeke, W., Pérez-Cueto, F.J.A., Kozioł-Kozakowska, A., Piórecka, B., Niedzwiedzka, B., D’Addesa, D., Saba, A., Turrini, A., Aschemann-Witzel, J., O Bech-Larsen, T., Strand, M., Wills, J., Traill, W.B., 2012. Policies to promote healthy eating in Europe: A structured review of instruments and their effectiveness, Nutrition Reviews 70(3): 188-200. DOI: 10.1111/j.1753-4887.2011.00442.x.

Capacci, S., Mazzocchi, M., 2011. Five-a-day, a price to pay: an evaluation of the UK program impact accounting for market forces, Journal of Health Economics, 30: 87-98. DOI: 10.1016/j.jhealeco.2010.10.006.

Cowell, S.J., Parkinson, S., 2003. Localisation of UK food production: an analysis using land area and energy as indicators. Agriculture, Ecosystems and Environment, 94(2): 221-236. DOI:10.1016/S0167-8809(02)00024-5

Deaton, A., Muellbauer, J., 1980. An almost ideal demand system. The American Economic Review, 70(3), 312-326.

Foster, C., Guében, C., Holmes, M., Wiltshire, J., Wynn, S., 2014. The environmental effects of seasonal food purchase: a raspberry case study. Journal of Cleaner Production, 73: 269-274. DOI: $10.1016 /$ j.jclepro.2013.12.077

Garnett, T., 2006. Fruit and Vegetables and UK Greenhouse Gas Emissions: Exploring the relationship. FCRN working paper 06-01 Rev. A.

Garnett, T., 2011. Where are the best opportunities for reducing greenhouse gas emissions in the food system (including the food chain)?, Food Policy, 36(1): S23-S32. DOI: 10.1016/j.foodpol.2010.10.010.

Green, R., Milner, J., Dangour, A.D., Haines, A., Chalabi, Z., Markandya, A., Spadaro, J., Wilkinson, P., 2015, The potential to reduce greenhouse gas emissions in the UK through healthy and realistic dietary change, Climatic Change, 129:253-265 DOI: 10.1007/s10584015-1329-y.

Griffith, R., O'Connell, M., Smith, K., 2013. Food expenditure and nutritional quality over the Great Recession, Institute for Fiscal Studies. DOI: 10.1920/BN.IFS.2012.00143.

Griffith, R., O'Connell, M., Smith, K., 2016. Shopping around: How households adjusted food spending over the Great Recession, Economica, 83 (330): 247-280 DOI: 10.1111/ecca.12166.

Jebb, S. A., Aveyard, P. N., Hawkes, C., 2013. Obesity policy in England. Obesity Reviews, 14: 42-59. DOI:10.1111/obr.12093 
Jones, N.R.V., Conklin, A.I., Suhrcke, M., Monsivais, P., 2014. The Growing Price Gap between More and Less Healthy Foods: Analysis of a Novel Longitudinal UK Dataset. PLoS ONE 9(10): e109343. DOI:10.1371/journal.pone.0109343.

Hallström, E., Röös, E., Börjesson, P., 2014. Sustainable meat consumption: A quantitative analysis of nutritional intake, greenhouse gas emissions and land use from a Swedish perspective. Food Policy, 47: 81-90. DOI: 10.1016/j.foodpol.2014.04.002.

Heckman, J.J., 2008. Econometric Causality, International Statistical Review, 76(1): 1-27 DOI:10.1111/j.1751-5823.2007.00024.x.

Hoolohan, C., Berners-Lee, M., McKinstry-West J., Hewitt, C.N., 2013. Mitigating the greenhouse gas emissions embodied in food through realistic consumer choices. Energy Policy, 63, 1065-1074. DOI: 10.1016/j.enpol.2013.09.046.

Irz, X., Leroy, P., Réquillart, V., Soler, L-G., 2016. Welfare and sustainability effects of dietary recommendations, Ecological Economics, 130: 139-155. DOI: 10.1016/j.ecolecon.2016.06.025.

Lucas, P., Jessiman, T., Cameron, A., 2015. Healthy Start: The Use of Welfare Food Vouchers by Low-Income Parents in England. Social Policy and Society, 14(3): 457-469. DOI:10.1017/S1474746415000020.

Macdiarmid, J.I., 2014. Seasonality and dietary requirements: will eating seasonal food contribute to health and environmental sustainability?, Proceedings of the Nutrition Society, 73(3), 368-375. DOI: 10.1017/S0029665113003753

Manning, L., 2016. Enabling UK consumers to increase their consumption of fruit and vegetables, Royal Agricultural University, Circenster (UK).

Masset, G., Soler, L-G., Vieux, F., Darmon, N., 2014. Identifying Sustainable Foods: The Relationship between Environmental Impact, Nutritional Quality, and Prices of Foods Representative of the French Diet, Journal of the Academy of Nutrition and Dietetics, 114(6): 862-869. DOI: 10.1016/j.jand.2014.02.002.

Michalsky, M., Hooda, P.S., 2015. Greenhouse gas emissions of imported and locally produced fruit and vegetable commodities: A quantitative assessment. Environmental Science and Policy, 48: 32-43. DOI: 10.1016/j.envsci.2014.12.018

Milà i Canals, L., Cowell, S.J., Sims, S., Besson, L., 2007. Comparing domestic versus imported apples: a focus on energy use. Environmental Science Pollution Research, 14(5): 338-344. DOI: $10.1065 /$ espr2007.04.412

Milà i Canals, L., Muñoz, I., Hospido, A., Plassmann, K., McLaren. S., 2008. Life Cycle Assessment (LCA) of Domestic vs. Imported Vegetables. Case studies on broccoli, salad crops and green beans. CES Working Paper 01/08.

Milner, J., Green, R., Dangour, A.D., et al. 2015. Health effects of adopting low greenhouse gas emission diets in the UK. BMJ Open, 2015;5:e007364. DOI:10.1136/bmjopen-2014-007364

NatCen Social Research, University College London, 2018. National Diet and Nutrition Survey Years 1-8, 2008/09-2015/16. [data collection]. 9th Edition. UK Data Service. SN: 6533. DOI: 10.5255/UKDA-SN-6533-8.

OECD, 2009. What are equivalence scales? available at: www.oecd.org/dataoecd/61/52/35411111.pdf.

Office for National Statistics, 2002. The National Diet \& Nutrition Survey: adults aged 19 to 64 years. Volume 1. London, United Kingdom.

Office for National Statistics, 2012. Living Cost and Food Survey: Quality and Methodology Information. London, United Kingdom. Available at: www.ons.gov.uk/ons/guidemethod/method-quality/quality/quality-information/economy/summary-quality-report-forthe-living-costs-and-food-survey--lcf-.pdf.

Office for National Statistics, 2014. Results from Years 5 and 6 (combined) of the Rolling Programme (2012/2013 - 2013/2014). London, United Kingdom. 
Office for National Statistics, Department for Environment, Food and Rural Affairs, 2017. Living Costs and Food Survey, 2001-2014 [data collection], 2nd Edition. UK Data Service. SN: 8210. DOI: $10.5255 / \mathrm{UKDA}-\mathrm{SN}-8210-4$.

Parajuli, R., Thoma, G., Matlock, M.D., 2019. Environmental sustainability of fruit and vegetable production supply chains in the face of climate change: A review, Science of The Total Environment, 650(2): 2863-2879. DOI: 10.1016/j.scitotenv.2018.10.019.

Pollard, C., Miller, M., Daly, A., Crouchley, K., O’Donoghue, K., Lang, A., Binns, C., 2008. Increasing fruit and vegetable consumption: Success of the Western Australian Go for $2 \& 5$ campaign. Public Health Nutrition, 11(3): 314-320. DOI:10.1017/S1368980007000523.

Pomerleau, J., Lock, K., Knai, C., McKee, M., 2005, Interventions Designed to Increase Adult Fruit and Vegetable Intake Can Be Effective: A Systematic Review of the Literature, Journal of Nutrition, 135(10): 2486-95. DOI: 0022-3166/05.

Reynolds C.J., Buckley J.D., Weinstein P., Boland J., 2014. Are the Dietary Guidelines for Meat, Fat, Fruit and Vegetable Consumption Appropriate for Environmental Sustainability? A Review of the Literature, Nutrients, 6, 2251-2265; DOI:10.3390/nu6062251.

Rooney C., McKinley M.C., Appleton K.M., Young I.S., McGrath A.J., Draffin C.R., Hamill L.L., Woodside J.V., 2017. How much is '5-a-day'? A qualitative investigation into consumer understanding of fruit and vegetable intake guidelines. Journal of Human Nutritional and Dietetics, 30, 105-113. DOI: 10.1111/jhn.12393.

Röös, E., \& Karlsson, H. (2013). Effect of eating seasonal on the carbon footprint of Swedish vegetable consumption. Journal of Cleaner Production, 59, 63-72. DOI: 10.1016/j.jclepro.2013.06.035

Russel, D., 2007. The United Kingdom's Sustainable Development Strategies: Leading the Way or Flattering to Deceive? European Environment, 17, 189-200. DOI: 10.1002/eet.449

Shankar, B., Brambila Macias, J., Traill, B., Mazzocchi, M., Capacci, S., 2013. An evaluation of the UK Food Standards Agency's salt campaign. Health Economics, 22: 243-250. DOI:10.1002/hec.2772.

Silva, A., Higgins, L. M. and Hussein, M., 2015. An Evaluation of the Effect of Child Directed Television Food Advertising Regulation in the United Kingdom. Canadian Journal of Agricultural Economics/Revue canadienne d'agroeconomie, 63: 583-600. DOI:10.1111/cjag.12078.

Sim, S., Barry, M., Clift, R., Cowell, S., 2007. The relative importance of transport in determining an appropriate sustainability strategy for food sourcing. A case study of fresh produce supply chains. International Journal of Life Cycle Assessment, 12:422-431. DOI: 10.1065/lca2006.07.259.

Stables, G.J., Subar, A.F., Patterson, B.H., Dodd, K., Heimendinger, J., Van Duyn, M.A.S., Nebeling, L., 2002. Changes in vegetable and fruit consumption and awareness among US adults: results of the 1991 and 19975 a day for better health program surveys. Journal of the American Dietetic Association, 102, 809-817. DOI: 10.1016/S0002-8223(02)90181-1.

Tukker, A., Goldbohm, R.A., de Koning, A., Verheijden, M., Kleijn, R.,Wolf, O., PérezDomínguez, I., Rueda-Cantuche, J.M., 2011. Environmental impacts of changes to healthier diets in Europe, Ecological Economics, 70, 1776-1788. DOI:10.1016/j.ecolecon.2011.05.001.

Van Dooren, C., Marinussen, M., Blonk, H., Aiking, H., Vellinga, P., 2014. Exploring dietary guidelines based on ecological and nutritional values: A comparison of six dietary patterns, Food Policy, 44: 36-46. DOI: 10.1016/j.foodpol.2013.11.002.

Vermeir, I., Verbeke, W. J., 2006. Sustainable Food Consumption: Exploring the Consumer "Attitude - Behavioral Intention" Gap. Journal of Agricultural and Environmental Ethics, 19: 169. DOI: 10.1007/s10806-005-5485-3.

Whitton, C., Nicholson, S., Roberts, C., Prynne, C., Pot, G., Olson, A., Fitt, E., Cole, D., Teucher, B., Bates, B., Henderson, H, Pigott, S., Deverill, C., Swan, G., Stephen, A. (2011). National Diet and Nutrition Survey: UK food consumption and nutrient intakes from the first year of 
the rolling programme and comparisons with previous surveys, British Journal of Nutrition, 106(12), 1899-1914. DOI:10.1017/S0007114511002340.

Wilson, N., Nghiem, N., Ni Mhurchu, C., Eyles, H., Baker, M.G., Blakely, T., 2013. Foods and Dietary Patterns That Are Healthy, Low-Cost, and Environmentally Sustainable: A Case Study of Optimization Modeling for New Zealand, PLoS ONE 8(3): e59648. DOI: 10.1371/journal.pone.0059648.

World Health Organization, 2003. Diet, nutrition and the prevention of chronic disease. WHO Technical Report Series 916; World Health Organization: Geneva. 


\section{Figures}

Figure 1: Weighted quantities consumption over the period 2001-2014 $(2002=100)$

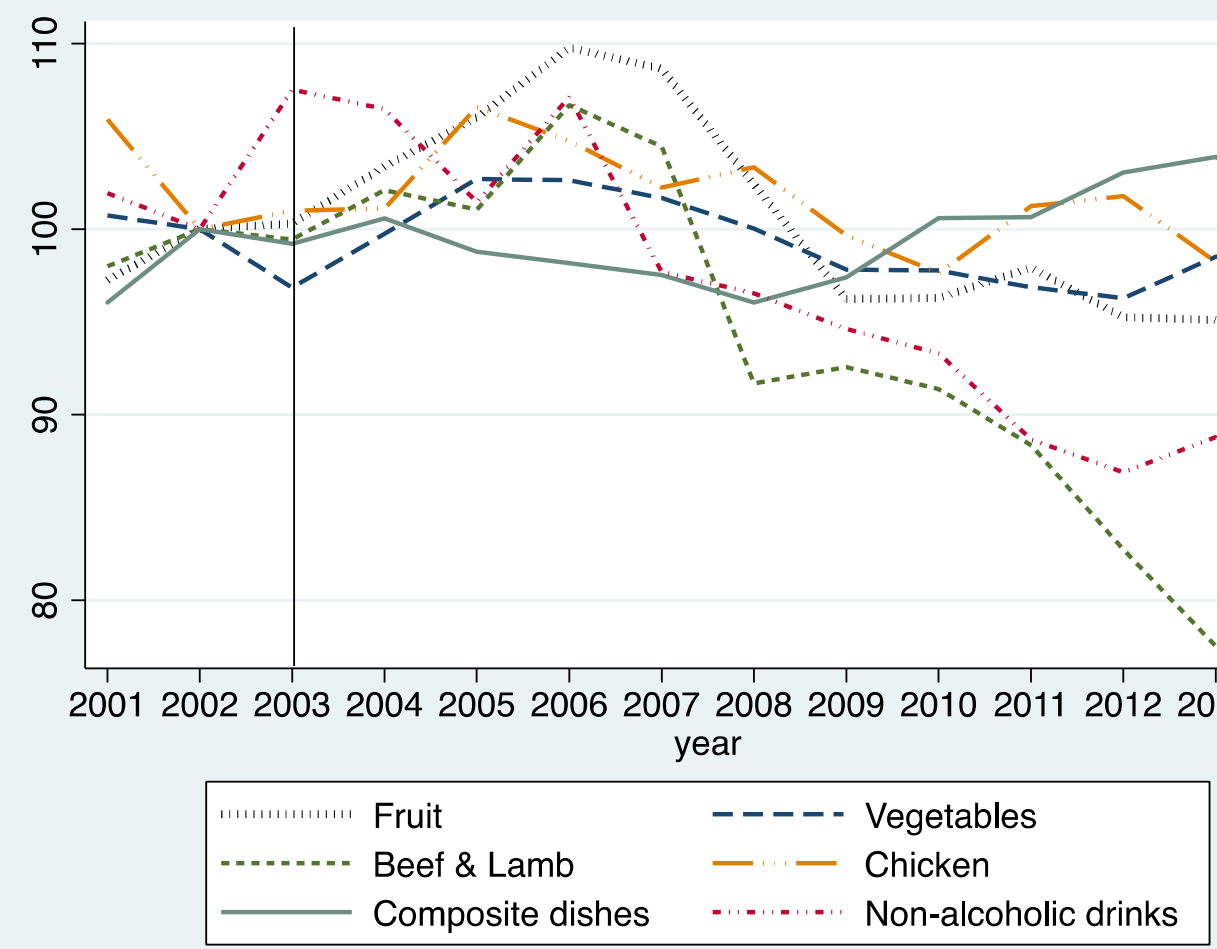

Source: our processing on data from the UK Expenditure and Food Surveys, and Living Cost and Food Surveys (Office for National Statistics and DEFRA, 2017) 


\section{Tables}

Table 1: Greenhouse gas emission factors for food categories and fruit and vegetables (Kg CO2e/Kg)

\begin{tabular}{lc}
\hline Product & GHGE \\
\hline 1. Fruit & \\
$\quad$ Fresh citrus fruits & 0.90 \\
$\quad$ Apples and pears & 0.66 \\
Stone fruits \& grapes & 1.80 \\
Berries & 3.42 \\
Bananas & 0.60 \\
$\quad$ Melons & 1.21 \\
Tinned fruit & 1.58 \\
$\quad$ Dried fruit & 4.26 \\
$\quad$ Frozen fruit & 2.77 \\
2. Vegetables & \\
Other vegetables & 2.13 \\
Salad & 3.66 \\
Prepared vegetables & 2.73 \\
Other roots & 0.6 \\
Mushrooms & 4.4 \\
Tomatoes & 4.2 \\
Tinned vegetables & 2.34 \\
Frozen vegetables & 3.06 \\
Dried vegetables, nuts and seeds & 4.26 \\
3. Potatoes & 0.338 \\
4. Cereals & 1.882 \\
5. Beef \& Lamb & 22.484 \\
6. Chicken & 4.050 \\
7. Pork & 10.290 \\
8. Other meats & 12.770 \\
9. Fish & 2.931 \\
10. Milk \& yoghurt & 3.270 \\
11. Butter, cheese \& other dairy & 11.588 \\
12. Eggs & 4.900 \\
13. Oils \& fats & 2.563 \\
14. Composite dishes & 5.490 \\
15. Alcoholic drinks & 1.803 \\
16. Non-alcoholic drinks & 0.898 \\
17. Confectionery & 3.752 \\
18. Crisps \& snacks & 0.297 \\
\hline
\end{tabular}

Source: our aggregations based on estimates from Hoolohan et al. (2013) 
Table 2: Sample descriptive statistics, purchases, prices and GHGEs

\begin{tabular}{|c|c|c|c|c|c|c|}
\hline \multirow{2}{*}{$\begin{array}{l}\text { Purchase data (adult equivalent) } \\
\text { Fruit }\end{array}$} & \multicolumn{2}{|c|}{$\begin{array}{l}\text { Quantities } \\
\text { (Kg./month) }\end{array}$} & \multicolumn{2}{|c|}{$\begin{array}{l}\text { Prices } \\
(\mathfrak{f} / \mathrm{Kg} .)\end{array}$} & \multicolumn{2}{|c|}{$\begin{array}{l}\text { GHGEs } \\
\text { (Kg. CO2e } / \\
\text { month) }\end{array}$} \\
\hline & 4.48 & $(4.56)$ & 1.88 & $(0.38)$ & 6.3 & $(5.41)$ \\
\hline Vegetables & 5.76 & $(4.96)$ & 2.03 & $(0.42)$ & 16.5 & $(8.40)$ \\
\hline Potatoes & 3.54 & $(4.46)$ & 0.99 & $(0.21)$ & 1.2 & $(2.59)$ \\
\hline Cereals & 5.15 & $(3.75)$ & 1.89 & $(0.38)$ & 9.7 & $(5.15)$ \\
\hline Beef \& Lamb & 0.88 & $(1.61)$ & 6.74 & (1.48) & 19.7 & $(7.63)$ \\
\hline Chicken & 1.31 & $(1.93)$ & 5.58 & $(0.97)$ & 5.3 & $(3.88)$ \\
\hline Pork & 0.69 & $(1.18)$ & 6.23 & $(0.81)$ & 7.1 & $(3.79)$ \\
\hline Other meats & 1.27 & $(1.45)$ & 6.11 & $(1.20)$ & 16.2 & $(5.17)$ \\
\hline Fish & 0.40 & $(0.87)$ & 7.61 & (2.06) & 1.2 & $(1.49)$ \\
\hline Milk \& Yoghurt & 10.39 & $(7.71)$ & 1.00 & $(0.20)$ & 34.0 & $(13.95)$ \\
\hline Butter, cheese \& other dairy & 0.88 & $(0.96)$ & 5.53 & $(0.89)$ & 10.2 & $(3.27)$ \\
\hline Eggs & 0.57 & $(0.85)$ & 2.64 & $(0.61)$ & 2.8 & $(1.88)$ \\
\hline Oils \& Fats & 0.80 & $(1.25)$ & 3.20 & $(0.66)$ & 2.0 & $(2.01)$ \\
\hline Composite Dishes & 2.45 & (2.49) & 4.53 & $(0.65)$ & 13.4 & $(5.84)$ \\
\hline Alcoholic drinks & 4.09 & $(8.39)$ & 5.52 & (1.38) & 7.4 & $(11.27)$ \\
\hline Non-alcoholic drinks & 10.83 & $(12.45)$ & 0.82 & $(0.19)$ & 9.7 & (11.80) \\
\hline Confectionery & 3.60 & $(3.38)$ & 3.39 & $(0.69)$ & 13.5 & $(6.55)$ \\
\hline Crisps \& Snacks & 0.37 & $(0.48)$ & 6.96 & $(1.26)$ & 0.1 & $(0.26)$ \\
\hline Miscellaneous Foods & 1.03 & $(1.14)$ & 8.17 & $(2.32)$ & 1.0 & $(1.14)$ \\
\hline Number of observations & & 84,356 & & & & \\
\hline
\end{tabular}

Source: UK Expenditure and Food Surveys and Living Cost Survey (ONS-DEFRA, 2017). Notes: Standard errors in brackets. GHGEs are based on composite emission factors based on estimates from Hoolohan et al. (2013) as reported in Table 1. 


\section{Table 3: Sample descriptive statistics, household characteristics}

\begin{tabular}{|c|c|c|c|c|c|c|}
\hline \multirow[b]{2}{*}{ Household characteristic } & \multicolumn{2}{|c|}{ (2001-2014) } & \multicolumn{2}{|c|}{$\begin{array}{l}\text { Pre-policy } \\
\text { (2001-2003) }\end{array}$} & \multicolumn{2}{|c|}{$\begin{array}{l}\text { Post-policy } \\
(2003-2014)\end{array}$} \\
\hline & Mean & Std. Dev. & Mean & Std. Dev. & Mean & Std. \\
\hline Total food expenditure (£ per capita/week $)^{a}$ & 121.14 & $(73.39)$ & 100.85 & $(57.56)$ & 124.44 & $(74.50)$ \\
\hline Real food expenditure $(2014 £ / p c / w)^{a, b}$ & 119.36 & $(70.90)$ & 121.78 & $(70.98)$ & 118.86 & $(70.88)$ \\
\hline Income $(£ / p c / \text { week })^{\mathrm{a}}$ & 357.61 & $(260.55)$ & 296.98 & $(288.13)$ & 356.78 & $(271.93)$ \\
\hline Real income $(2014 £ / p c / w)^{a, c}$ & 427.28 & $(352.91)$ & 432.95 & $(419.46)$ & 426.12 & $(337.61)$ \\
\hline Age in years of HRP & 51.79 & $(16.93)$ & 51.07 & $(16.92)$ & 52.46 & $(16.49)$ \\
\hline Age at which education was completed (HRP) & 15.65 & $(6.26)$ & 16.74 & $(2.72)$ & 15.52 & $(6.33)$ \\
\hline Married $(\mathrm{HRP})=1$ & 0.58 & $(0.49)$ & 0.60 & $(0.49)$ & 0.59 & $(0.49)$ \\
\hline Retired $(\mathrm{HRP})=1$ & 0.40 & $(0.49)$ & 0.40 & $(0.49)$ & 0.42 & $(0.49)$ \\
\hline Unemployed $($ HRP $)=1$ & 0.03 & $(0.18)$ & 0.03 & $(0.16)$ & 0.03 & $(0.17)$ \\
\hline Household with child $<18=1$ & 0.30 & $(0.46)$ & 0.33 & $(0.47)$ & 0.31 & $(0.46)$ \\
\hline Number of observations & 84,356 & & 14,381 & & 69,975 & \\
\hline
\end{tabular}

Source: Our processing of data from the UK Expenditure and Food Surveys and Living Cost Survey (various years), ONS-DEFRA (2017).

Notes:

${ }^{a}$ Per capita data are computed based on OECD equivalence scales.

${ }^{b}$ Real data are computed by deflating nominal values by the ONS food retail price index

${ }^{\mathrm{c}}$ Real data are computed by deflating nominal values by the ONS all items retail price index 
Table 4: 5-a-day impact on purchased quantities (Kg/person/month)

\begin{tabular}{lcccccc}
\hline & \multicolumn{2}{c}{ 2003-2014 } & \multicolumn{2}{c}{ Post-policy sample } & \multicolumn{2}{c}{ 2003-2008 } \\
Food Group & $\bar{\delta}_{i t}$ & & $\bar{\delta}_{i t}$ & \multicolumn{2}{c}{$\bar{\delta}_{i t}$} & \\
\hline Fruit & $+0.776^{* *}$ & $(0.072)$ & $+0.716^{* *}$ & $(0.038)$ & $+0.619^{* *}$ & $(0.097)$ \\
Vegetables & $+0.397^{* *}$ & $(0.065)$ & $+0.163^{* *}$ & $(0.023)$ & $+0.453^{* *}$ & $(0.089)$ \\
Potatoes & $-0.335^{* *}$ & $(0.034)$ & $-0.621^{* *}$ & $(0.022)$ & $+0.136^{* *}$ & $(0.061)$ \\
Cereals & $-0.213^{* *}$ & $(0.017)$ & $-0.731^{* *}$ & $(0.031)$ & $+0.291^{* *}$ & $(0.021)$ \\
Beef \& Lamb & $-0.064^{* *}$ & $(0.020)$ & $+0.035^{* *}$ & $(0.017)$ & $-0.144^{* *}$ & $(0.025)$ \\
Chicken & -0.009 & $(0.013)$ & $+0.047^{* *}$ & $(0.009)$ & -0.018 & $(0.018)$ \\
Pork & $-0.128^{* *}$ & $(0.012)$ & $-0.035^{* *}$ & $(0.007)$ & $-0.195^{* *}$ & $(0.014)$ \\
Other meats & $-0.053^{* *}$ & $(0.015)$ & $+0.017^{* *}$ & $(0.007)$ & $-0.060^{* *}$ & $(0.021)$ \\
Fish & $+0.070^{* *}$ & $(0.006)$ & $+0.073^{* *}$ & $(0.004)$ & $+0.042^{* *}$ & $(0.007)$ \\
Milk \& yoghurt & $-0.109^{* *}$ & $(0.052)$ & $-1.038^{* *}$ & $(0.079)$ & $+0.407^{* *}$ & $(0.079)$ \\
Butter, cheese \& other dairy & $-0.008^{* *}$ & $(0.005)$ & $-0.086^{* *}$ & $(0.005)$ & $+0.054^{* *}$ & $(0.007)$ \\
Eggs & $-0.007^{* *}$ & $(0.004)$ & $-0.087^{* *}$ & $(0.007)$ & $+0.073^{* *}$ & $(0.004)$ \\
Oils \& fats & $-0.008^{* *}$ & $(0.003)$ & $-0.058^{* *}$ & $(0.004)$ & $+0.066^{* *}$ & $(0.005)$ \\
Composite dishes & $-0.033^{* *}$ & $(0.012)$ & $+0.118^{* *}$ & $(0.025)$ & $-0.145^{* *}$ & $(0.014)$ \\
Alcoholic drinks & $+0.372^{* *}$ & $(0.017)$ & $+0.600^{* *}$ & $(0.021)$ & $+0.092^{* *}$ & $(0.015)$ \\
Non-alcoholic drinks & $-0.062^{* *}$ & $(0.025)$ & -0.031 & $(0.031)$ & $-0.271^{* *}$ & $(0.033)$ \\
Confectionery & $-0.428^{* *}$ & $(0.018)$ & $-0.474^{* *}$ & $(0.012)$ & $-0.325^{* *}$ & $(0.022)$ \\
Crisps \& snacks & $-0.044^{* *}$ & $(0.007)$ & $-0.049^{* *}$ & $(0.006)$ & $-0.021^{* *}$ & $(0.008)$ \\
Miscellaneous food & $-0.056^{* *}$ & $(0.005)$ & $-0.077^{* *}$ & $(0.009)$ & $-0.010^{* *}$ & $(0.003)$ \\
\hline TOTAL & +0.060 & $(0.123)$ & $-1.516^{* *}$ & $(0.086)$ & $+1.044^{* *}$ & 0.155 \\
\hline & & & & & &
\end{tabular}

Notes: ${ }^{* *} \mathrm{p}<0.01 ;{ }^{*} \mathrm{p}<0.05$. Clustered Standard Errors in brackets. 
Table 5. Impact of the 5-a-day campaign by type of fruit and vegetables: expenditure shares, purchased quantities and GHGEs (2003-2014)

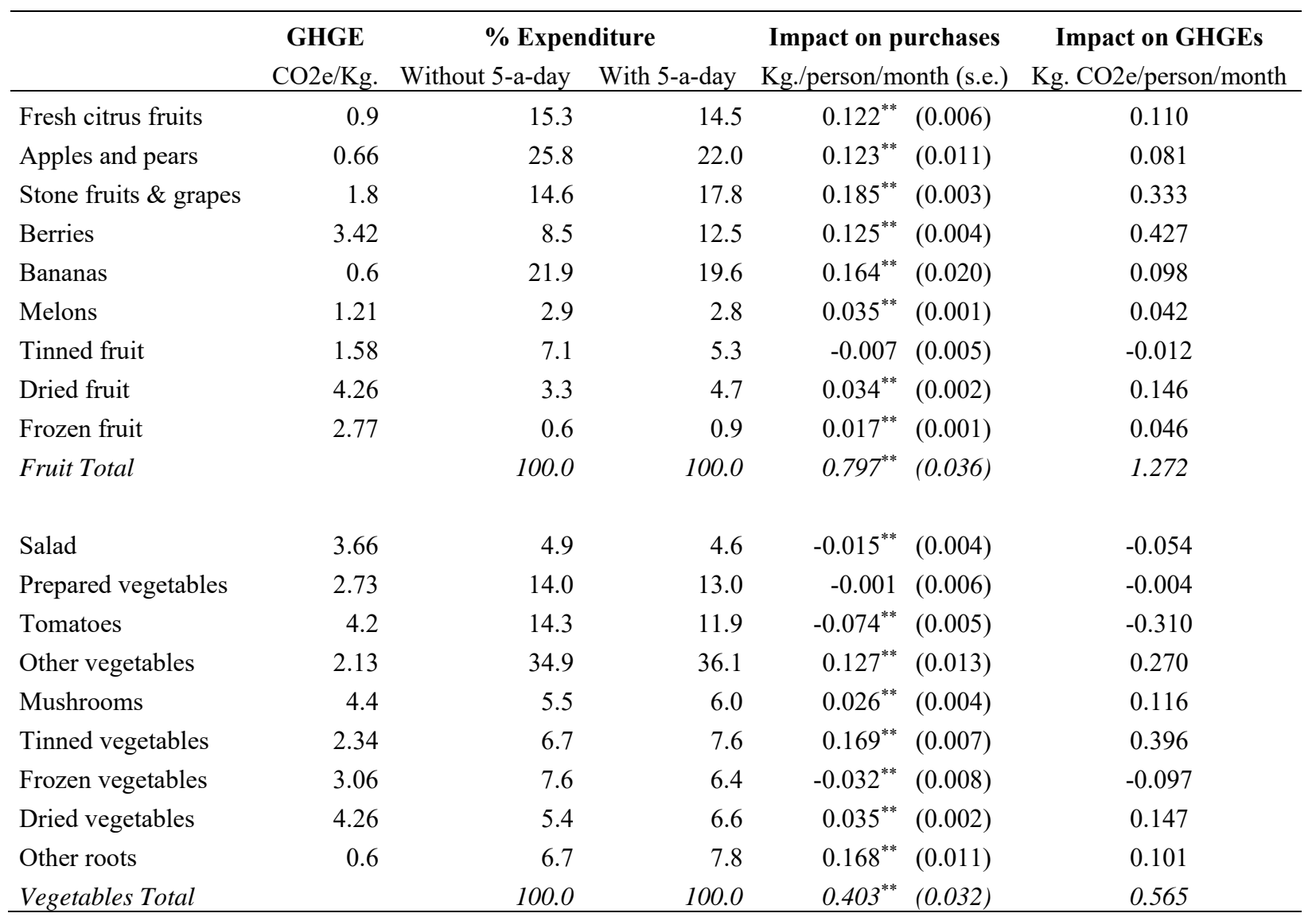

Notes: $* * \mathrm{p}<0.01 ; * \mathrm{p}<0.05$. Clustered Standard Errors in brackets 
Table 6. UK imports of Fruit and Vegetables

\begin{tabular}{lrrrrrr}
\hline & \multicolumn{3}{c}{ Imports $(, 000$ tons $)$} & \multicolumn{3}{c}{ \% of domestic disappearances } \\
& $2001-2002$ & $2003-2008$ & $2009-2014$ & $2001-2002$ & $2003-2008$ & $2009-2014$ \\
\hline & & & & & & \\
Fresh citrus fruits & 703 & 774 & 700 & 104.3 & 105.1 & 106.7 \\
Apples and pears & 570 & 644 & 854 & 72.9 & 76.2 & 61.8 \\
Stone fruits \& grapes & 589 & 590 & 664 & 98.7 & 101.0 & 101.2 \\
Berries & 39 & 64 & 80 & 39.3 & 40.0 & 38.8 \\
Bananas & 796 & 926 & 1071 & 100.4 & 102.6 & 102.8 \\
Melons & 170 & 209 & 210 & 104.3 & 103.1 & 101.1 \\
Fruit Total & $\mathbf{2 8 6 7}$ & $\mathbf{3 2 0 7}$ & $\mathbf{3 5 7 9}$ & $\mathbf{9 2 . 2}$ & $\mathbf{9 3 . 4}$ & $\mathbf{8 6 . 2}$ \\
& & & & & & \\
Salad & 158 & 182 & 164 & 39.1 & 41.7 & 37.4 \\
Tomatoes & 312 & 416 & 415 & 101.6 & 101.1 & 101.2 \\
Other vegetables & 684 & 759 & 905 & 47.5 & 50.5 & 55.7 \\
Mushrooms & 74 & 110 & 104 & 100.2 & 100.2 & 100.4 \\
Dried vegetables & 197 & 235 & 243 & 62.9 & 62.3 & 59.8 \\
Other roots & 90 & 50 & 46 & 8.2 & 5.2 & 4.7 \\
Vegetables Total & $\mathbf{1 7 3 3}$ & $\mathbf{2 1 0 2}$ & $\mathbf{2 2 8 0}$ & $\mathbf{4 5 . 8}$ & $\mathbf{5 1 . 1}$ & $\mathbf{5 2 . 5}$ \\
& & & & & & \\
\hline
\end{tabular}

Source: Our processing of data from DEFRA Horticultural Statistics 2016

Note: Figures are yearly averages in each period. Domestic disappearances are computed as production + imports - exports. They reflect internal uses (food, feed) and waste. 


\section{Table 7: 5-a-day impact on GHG emissions (Kg CO2e/person/month)}

\begin{tabular}{lccc}
\hline & \multicolumn{3}{c}{ Post-policy sample } \\
Food group & $\mathbf{2 0 0 3 - 2 0 1 4}$ & $\mathbf{2 0 0 3 - 2 0 0 8}$ & $\mathbf{2 0 0 9 - 2 0 1 4}$ \\
\hline Fruit & $\boldsymbol{\eta}_{\boldsymbol{i t}}$ & $\overline{\boldsymbol{\eta}}_{\boldsymbol{i t}}$ & $\boldsymbol{\boldsymbol { \eta }}_{\boldsymbol{i t}}$ \\
Vegetables & +1.27 & +1.10 & +1.18 \\
Potatoes & +0.57 & +0.12 & +0.56 \\
Cereals & -0.11 & -0.21 & +0.05 \\
Beef \& Lamb & -0.40 & -1.38 & +0.55 \\
Chicken & -1.43 & +0.78 & -3.23 \\
Pork & -0.04 & +0.19 & -0.07 \\
Other meats & -1.31 & -0.36 & -2.01 \\
Fish & -0.67 & +0.22 & -0.76 \\
Milk \& yoghurt & +0.20 & +0.21 & +0.12 \\
Butter, cheese \& other dairy & -0.36 & -3.39 & +1.33 \\
Eggs & -0.09 & -1.00 & +0.62 \\
Oils \& fats & -0.03 & -0.43 & +0.36 \\
Composite dishes & -0.02 & -0.15 & +0.17 \\
Alcoholic drinks & -0.18 & +0.65 & -0.79 \\
Non-alcoholic drinks & +0.67 & +1.08 & +0.17 \\
Confectionery & -0.06 & -0.03 & -0.24 \\
Crisps \& snacks & -1.60 & -1.78 & -1.22 \\
Miscellaneous food & -0.01 & -0.01 & -0.01 \\
\hline TOTAL & -0.06 & -0.08 & -0.01 \\
\hline & -3.66 & -4.27 & -3.23 \\
\hline
\end{tabular}

Note: conversions are based on composite emission factors based on estimates from Hoolohan et al. (2013) 


\section{Appendix}

Table A1: Sample size by year and quarter

\begin{tabular}{cccccc} 
Year & 1st Quarter & 2nd Quarter & 3rd Quarter & 4th Quarter & Total \\
\hline 2001 & & 1,803 & 1,882 & 1,913 & 5,598 \\
2002 & 1,864 & 1,686 & 1,767 & 1,717 & 7,034 \\
2003 & 1,749 & 1,787 & 1,720 & 1,742 & 6,998 \\
2004 & 1,780 & 1,593 & 1,767 & 1,702 & 6,842 \\
2005 & 1,821 & 1,642 & 1,629 & 1,682 & 6,774 \\
2006 & 1,713 & 1,684 & 1,653 & 1,573 & 6,623 \\
2007 & 1,465 & 1,461 & 1,606 & 1,585 & 6,117 \\
2008 & 1,440 & 1,423 & 1,507 & 1,446 & 5,816 \\
2009 & 1,465 & 1,446 & 1,483 & 1,424 & 5,818 \\
2010 & 1,312 & 1,305 & 1,359 & 1,272 & 5,248 \\
2011 & 1,393 & 1,442 & 1,448 & 1,390 & 5,673 \\
2012 & 1,463 & 1,421 & 1,376 & 1,310 & 5,570 \\
2013 & 1,281 & 1,283 & 1,295 & 1,273 & 5,132 \\
2014 & 1,303 & 1,315 & 1,224 & 1,271 & 5,113 \\
\hline Total & 20,049 & 21,291 & 21,716 & 21,300 & 84,356 \\
\hline
\end{tabular}




\section{Online Appendix}

Table A. Impact of the 5-a-day campaign on the allocation of fruit and vegetable expenditure, purchased quantities and GHGEs (2003-2008)

\begin{tabular}{lrrrrrc}
\hline & GHGE & \multicolumn{2}{c}{ \% Expenditure } & Impact on purchases & Impact on GHGEs \\
& CO2e/Kg. & Without 5-a-day & With 5-a-day & Kg./person/week (s.e.) & Kg. CO2e/person/week \\
\hline Fresh citrus fruits & 0.9 & 15.3 & 14.6 & 0.108 & $(0.006)$ & 0.097 \\
Apples and pears & 0.66 & 25.8 & 23.1 & 0.136 & $(0.013)$ & 0.090 \\
Stone fruits \& grapes & 1.8 & 14.6 & 17.3 & 0.164 & $(0.004)$ & 0.296 \\
Berries & 3.42 & 8.5 & 11.0 & 0.102 & $(0.004)$ & 0.349 \\
Bananas & 0.6 & 21.9 & 20.6 & 0.175 & $(0.012)$ & 0.105 \\
Melons & 1.21 & 2.9 & 2.9 & 0.039 & $(0.002)$ & 0.047 \\
Tinned fruit & 1.58 & 7.1 & 5.5 & -0.006 & $(0.006)$ & -0.010 \\
Dried fruit & 4.26 & 3.3 & 4.3 & 0.023 & $(0.002)$ & 0.097 \\
Frozen fruit & 2.77 & 0.6 & 0.8 & 0.011 & $(0.001)$ & 0.032 \\
Fruit Total & & 100.0 & 100.0 & 0.752 & 1.103 \\
& & & & & \\
Salad & & & & & \\
Prepared vegetables & 2.66 & 4.9 & 5.0 & -0.011 & $(0.005)$ & -0.040 \\
Tomatoes & 2.73 & 14.0 & 12.8 & -0.006 & $(0.004)$ & -0.017 \\
Other vegetables & 4.2 & 14.3 & 12.1 & -0.070 & $(0.007)$ & -0.293 \\
Mushrooms & 2.13 & 34.9 & 36.2 & 0.045 & $(0.009)$ & 0.096 \\
Tinned vegetables & 4.4 & 5.5 & 6.1 & 0.019 & $(0.004)$ & 0.082 \\
Frozen vegetables & 2.34 & 6.7 & 7.7 & 0.121 & $(0.007)$ & 0.284 \\
Dried vegetables & 3.06 & 7.6 & 6.3 & -0.051 & $(0.009)$ & -0.157 \\
Other roots & 4.26 & 5.4 & 6.2 & 0.024 & $(0.002)$ & 0.101 \\
Vegetables Total & 0.6 & 6.7 & 7.6 & 0.106 & $(0.006)$ & 0.063 \\
\hline
\end{tabular}


Table B. Impact of the 5-a-day campaign on the allocation of fruit and vegetable expenditure, purchased quantities and GHGEs (2009-2014)

\begin{tabular}{|c|c|c|c|c|c|}
\hline & \multirow{2}{*}{$\begin{array}{c}\text { GHGE } \\
\mathrm{CO} 2 \mathrm{e} / \mathrm{Kg} .\end{array}$} & \multicolumn{2}{|c|}{ \% Expenditure } & \multirow{2}{*}{$\begin{array}{l}\text { Impact on purchases } \\
\text { Kg./person/week (s.e.) }\end{array}$} & \multirow{2}{*}{$\begin{array}{c}\text { Impact on GHGEs } \\
\text { Kg. CO2e/person/week }\end{array}$} \\
\hline & & Without 5-a-day & With 5-a-day & & \\
\hline Fresh citrus fruits & 0.9 & 15.3 & 14.3 & $0.102 \quad(0.011)$ & 0.092 \\
\hline Apples and pears & 0.66 & 25.8 & 20.9 & $0.057 \quad(0.013)$ & 0.037 \\
\hline Stone fruits \& grapes & 1.8 & 14.6 & 18.4 & $0.179(0.006)$ & 0.321 \\
\hline Berries & 3.42 & 8.5 & 13.8 & $0.130 \quad(0.005)$ & 0.445 \\
\hline Bananas & 0.6 & 21.9 & 18.9 & $0.091 \quad(0.025)$ & 0.055 \\
\hline Melons & 1.21 & 2.9 & 2.5 & $0.019(0.003)$ & 0.022 \\
\hline Tinned fruit & 1.58 & 7.1 & 5.0 & $-0.018 \quad(0.004)$ & -0.028 \\
\hline Dried fruit & 4.26 & 3.3 & 5.2 & $0.041 \quad(0.001)$ & 0.174 \\
\hline Frozen fruit & 2.77 & 0.6 & 1.1 & $0.020(0.001)$ & 0.057 \\
\hline Fruit Total & & 100.0 & 100.0 & 0.621 & 1.175 \\
\hline Salad & 3.66 & 4.9 & 4.0 & $-0.029(0.005)$ & -0.107 \\
\hline Prepared vegetables & 2.73 & 14.0 & 13.4 & $-0.001 \quad(0.008)$ & -0.003 \\
\hline Tomatoes & 4.2 & 14.3 & 11.4 & $-0.102 \quad(0.006)$ & -0.428 \\
\hline Other vegetables & 2.13 & 34.9 & 35.8 & $0.115(0.024)$ & 0.245 \\
\hline Mushrooms & 4.4 & 5.5 & 6.0 & $0.027 \quad(0.005)$ & 0.121 \\
\hline Tinned vegetables & 2.34 & 6.7 & 7.6 & $0.206 \quad(0.011)$ & 0.483 \\
\hline Frozen vegetables & 3.06 & 7.6 & 6.7 & $-0.014 \quad(0.008)$ & -0.042 \\
\hline Dried vegetables & 4.26 & 5.4 & 6.9 & $0.040 \quad(0.002)$ & 0.169 \\
\hline Other roots & 0.6 & 6.7 & 8.1 & $0.208 \quad(0.018)$ & 0.125 \\
\hline Vegetables Total & & 100.0 & 100.0 & 0.451 & 0.563 \\
\hline
\end{tabular}


Table C: 5-a-day impact on purchased quantities without the application of equivalence scales $(\mathrm{Kg} / \mathrm{hh} / \mathrm{month})$

\begin{tabular}{|c|c|c|c|c|c|c|}
\hline \multirow{2}{*}{$\begin{array}{l}\text { Food } \\
\text { Fruit }\end{array}$} & \multicolumn{2}{|c|}{$\bar{\delta}_{i t}^{2003-2014}$} & \multicolumn{2}{|c|}{ 2003-2008 } & \multicolumn{2}{|c|}{ 2009-2014 } \\
\hline & $+1.326^{* *}$ & $(0.072)$ & $+1.290 * *$ & $(0.038)$ & $+0.979 * *$ & $(0.097)$ \\
\hline Vegetables & $+0.565^{* *}$ & $(0.065)$ & $+0.231 * *$ & $(0.023)$ & $+0.580 * *$ & (0.089) \\
\hline Potatoes & $-0.538 * *$ & $(0.034)$ & $-1.122 * *$ & $(0.022)$ & $+0.374 * *$ & $(0.061)$ \\
\hline Cereals & $-0.369 * *$ & $(0.017)$ & $-1.331 * *$ & $(0.031)$ & $+0.563 * *$ & $(0.021)$ \\
\hline Beef \& Lamb & $-0.074 * *$ & $(0.020)$ & $+0.082 * *$ & $(0.017)$ & $-0.197 * *$ & $(0.025)$ \\
\hline Chicken & +0.010 & $(0.013)$ & $+0.104 * *$ & $(0.009)$ & +0.005 & $(0.018)$ \\
\hline Pork & $-0.213 * *$ & $(0.012)$ & $-0.063 * *$ & $(0.007)$ & $-0.318 * *$ & $(0.014)$ \\
\hline Other meats & $-0.066^{* *}$ & $(0.015)$ & $+0.030 * *$ & $(0.007)$ & $-0.048^{*}$ & $(0.021)$ \\
\hline Fish & $+0.122 * *$ & $(0.006)$ & $+0.136^{* *}$ & $(0.004)$ & $+0.064 * *$ & $(0.007)$ \\
\hline Milk \& yoghurt & $-0.302 * *$ & $(0.052)$ & $-1.949 * *$ & $(0.079)$ & $+0.574 * *$ & $(0.079)$ \\
\hline Butter, cheese $\&$ other dairy & $-0.016^{* *}$ & $(0.005)$ & $-0.152 * *$ & $(0.005)$ & $+0.092 * *$ & $(0.007)$ \\
\hline Eggs & $-0.009 *$ & $(0.004)$ & $-0.153 * *$ & $(0.007)$ & $+0.134 * *$ & $(0.004)$ \\
\hline Oils \& fats & $-0.015^{* *}$ & $(0.003)$ & $-0.105^{* *}$ & $(0.004)$ & $+0.121 * *$ & $(0.005)$ \\
\hline Composite dishes & $-0.070 * *$ & $(0.012)$ & $+0.210 * *$ & $(0.025)$ & $-0.276^{* *}$ & $(0.014)$ \\
\hline Alcoholic drinks & $+0.657 * *$ & $(0.017)$ & $+1.106^{* *}$ & $(0.021)$ & $+0.114 * *$ & $(0.015)$ \\
\hline Non-alcoholic drinks & $-0.146^{* *}$ & $(0.025)$ & -0.038 & $(0.031)$ & $-0.585 * *$ & $(0.033)$ \\
\hline Confectionery & $-0.782 * *$ & $(0.018)$ & $-0.881 * *$ & $(0.012)$ & $-0.585 * *$ & $(0.022)$ \\
\hline Crisps \& snacks & $-0.081 * *$ & $(0.007)$ & $-0.096 * *$ & $(0.006)$ & $-0.035 * *$ & $(0.008)$ \\
\hline Miscellaneous food & $-0.102 * *$ & $(0.005)$ & $-0.143 * *$ & $(0.009)$ & $-0.017 * *$ & $(0.003)$ \\
\hline TOTAL & -0.102 & $(0.123)$ & $-2.844 * *$ & $(0.086)$ & $\begin{array}{r}+1.538^{*} \\
*\end{array}$ & (0.155) \\
\hline
\end{tabular}


Table D: 5-a-day impact on GHG emissions without the application of equivalence scales (Kg CO2e/hh/month)

\begin{tabular}{lccc}
\hline Food & $\mathbf{2 0 0 3 - 2 0 1 4}$ & $\mathbf{2 0 0 3 - 2 0 0 8}$ & $\mathbf{2 0 0 9 - 2 0 1 4}$ \\
& $\overline{\boldsymbol{\eta}}_{\boldsymbol{i t}}$ & $\overline{\boldsymbol{\eta}}_{\boldsymbol{i t}}$ & $\overline{\boldsymbol{\eta}}_{\boldsymbol{i t}}$ \\
\hline Fruit & +1.86 & +1.81 & +1.38 \\
Vegetables & +1.62 & +0.66 & +1.66 \\
Potatoes & -0.18 & -0.38 & +0.13 \\
Cereals & -0.69 & -2.51 & +1.06 \\
Beef \& Lamb & -1.66 & +1.85 & -4.43 \\
Chicken & +0.04 & +0.42 & +0.02 \\
Pork & -2.20 & -0.65 & -3.27 \\
Other meats & -0.84 & +0.38 & -0.62 \\
Fish & +0.36 & +0.40 & +0.19 \\
Milk \& yoghurt & -0.99 & -6.37 & +1.88 \\
Butter, cheese \& other dairy & -0.18 & -1.76 & +1.06 \\
Eggs & -0.04 & -0.75 & +0.65 \\
Oils \& fats & -0.04 & -0.27 & +0.31 \\
Composite dishes & -0.39 & +1.15 & -1.52 \\
Alcoholic drinks & +1.18 & +1.99 & +0.21 \\
Non-alcoholic drinks & -0.13 & -0.03 & -0.53 \\
Confectionery & -2.93 & -3.31 & -2.20 \\
Crisps \& snacks & -0.02 & -0.03 & -0.01 \\
Miscellaneous food & -0.10 & -0.14 & -0.02 \\
\hline TOTAL & -5.33 & -7.52 & -4.03 \\
\hline
\end{tabular}




\section{TABLE E: Seasonal patterns in fruit \& vegetable purchases}

\begin{tabular}{lrrr}
\hline \multicolumn{4}{c}{ \% difference of average purchases } \\
& between spring+summer and autumn+winter & \\
& $2001-2002$ & & 2009-2014 \\
\hline & & & \\
Fresh citrus fruits & -31.0 & -29.2 & -28.6 \\
Apples and pears & -2.3 & -2.7 & -1.1 \\
Stone fruits \& grapes & -2.6 & 1.0 & 4.2 \\
Berries & 1008.7 & 623.6 & 231.6 \\
Bananas & 5.3 & 6.1 & 4.5 \\
Melons & 105.1 & 56.7 & 98.7 \\
Tinned fruit & 2.8 & -1.5 & -0.5 \\
Dried fruit & -20.5 & -28.7 & -20.1 \\
Frozen fruit & -23.9 & 33.6 & -11.6 \\
& & & \\
Salad & 1.1 & -3.3 & -0.6 \\
Prepared vegetables & 14.8 & 56.2 & 50.2 \\
Tomatoes & 5.2 & -0.7 & -1.8 \\
Other vegetables & -17.6 & -20.0 & -17.7 \\
Mushrooms & -9.2 & -3.9 & -9.7 \\
Tinned vegetables & 35.8 & 34.0 & 41.2 \\
Frozen vegetables & -1.8 & -8.9 & -4.7 \\
Dried vegetables & -14.9 & -12.0 & -12.4 \\
Other roots & -38.4 & -43.0 & -18.0 \\
& & & \\
\hline
\end{tabular}

\section{Notes:}

Average seasonal effects estimated through a regression model with quarterly dummies and yearly fixed effects. The indicator in the table represents the distance (in \%) between the aggregate quarterly effects for the spring and summer quarters and the aggregate quarterly effects for the autumn and winter quarters. Positive values indicate a higher consumption in spring and summer and vice versa (e.g, purchases of citrus fruit in spring and summer were on average $31 \%$ lower than those of autumn and winter over the 2001-2002 sample). Other indicators were tested (e.g. ratios between individual quarters), and they are all consistent with those of the above table. 